\title{
Brunei Student Teachers' Selected Personal Attributes, Attitudes to Women and Interpersonal Trust: Brief Psychological Report
}

\author{
Salwa Mahalle ${ }^{1}$, Rohani Matzin ${ }^{1}$, Malai Hayati Sheikh Hamid ${ }^{1}$, Masitah Shahrill ${ }^{1} \&$ Lawrence Mundia $^{1}$ \\ ${ }^{1}$ Sultan Hassanal Bolkiah Institute of Education, Universiti Brunei Darussalam, Bandar Seri Begawan, Brunei \\ Correspondence: Salwa Mahalle, Sultan Hassanal Bolkiah Institute of Education, Universiti Brunei Darussalam, \\ Jalan Tungku Link, Gadong BE 1410, Bandar Seri Begawan, Brunei Darussalam, Brunei. Tel: 673-246-3001. \\ E-mail: salwa.mahalle@ubd.edu.bn
}

\author{
Received: August 8, 2013 Accepted: November 24, 2013 Online Published: December 31, 2013 \\ doi:10.5539/ass.v10n1p151 URL: http://dx.doi.org/10.5539/ass.v10n1p151
}

\begin{abstract}
We report on the findings from three social psychology survey instruments administered to 78 randomly selected Brunei student teachers of both genders. Males scored significantly higher than females on the masculinity-femininity dimension of the personal attributes inventory. In addition, mean scores for males were also significantly higher than those of their female counterparts on the equal distribution of labor and equal social roles domains of the attitudes towards women scale. However, there were no significant differences among the participants by teacher training programs and race or ethnicity. These results suggest that men have no prejudices over women. The participants might be able to live and work together peacefully. This is important for promoting social harmony and stability in the Brunei teaching profession where more females than males are increasingly assuming positions of higher responsibility previously held by males. Further mixed-methods research was recommended to gain additional insights.
\end{abstract}

Keywords: student teachers, personal attributes, attitudes to women, interpersonal trust, social psychology

\section{Introduction}

The majority of teachers in Brunei are women. Female teachers in Brunei are also increasingly assuming positions of responsibility. Gone are the days when males were dominant in the teaching career in Brunei. Despite these changing circumstances, not much social psychology research has been conducted to determine how educational personnel of both genders are interacting and functioning during training and while serving as teachers in Brunei Darussalam. For example, much of the available psychological research regarding Brunei initial teachers has focused mainly on issues such as: the Brunei student teachers' mental health problems (Mundia, 2010a; b; c; Mundia, 2012a); effects of psychological distress on Brunei trainee teachers' academic achievement (Mundia, 2011a); assessment of psychological distress in Brunei female, mature age and part-time student teachers (Haq \& Mundia, 2013); attitudes of Brunei pre-service teachers of both genders to special and inclusive education (Haq \& Mundia, 2012); and improvement of Brunei teacher education programs (Mundia, 2009; Mundia, 2010d; Mundia, 2012b; Mundia, 2012c; Tait \& Mundia, 2012). In addition, although Brunei female students are relatively stronger at mathematics than their male counterparts, recent studies have shown that there some who experience problems with this subject, have high support needs, and would learn it more effectively in collaboration with peers of both genders (Mundia, 2010e; Mundia, 2012d; Hamid et al., 2013). The scant psychological research in Brunei may partly be attributed to lack of appropriate instruments to use. Most of the western instruments used are in English, which is spoken as a second language in Brunei, and tend to have reliability, validity and bias problems in the local context (Mundia \& Bakar, 2010; Mundia, 2011b).

\section{Objectives of the study}

Although a small country in terms of both land area and population, Brunei has now four universities. Two of them train teachers. The present study was conducted at one of these two. The purpose of the study was to determine student teachers' differences on selected personal attributes, attitudes to women, and interpersonal trust by gender, teacher training program, and ethnicity.

\section{Method}

The study used field survey approach to investigate the problem. This research strategy differs from the 
telephone and postal survey techniques in that the researcher has to go into the fields (relevant educational institutions in the present study) to collect the data. The rationale and justification for employing this research strategy was two-fold. First, we wanted to involve as many trainee teachers in the study as possible. Second, it was then possible give on-the-spot assistance to respondents who needed help to complete the data collection instruments correctly thereby increasing the number of usable returns.

\section{Sample}

Participants in the study were drawn randomly from among all the student teachers in the university. A total of 91 questionnaires were distributed to chosen students but only 78 submitted properly completed and usable protocols. Of the remaining 13, seven declined to complete the questionnaires, two did not complete the instruments properly (e.g. they tended to endorse the same scale values on most of the items) and the rest, four, were excluded due to having many missing values in the rating scales. The participants' bio-data (gender, ethnicity, program of study, and age) are presented in Table 1.

Table 1. Demographic information ( $\mathrm{N}=78)$

\begin{tabular}{llll}
\hline Variable & Group & Frequency & Percentage \\
\hline Gender & Females & 60 & 77 \\
& Males & 18 & 23 \\
Ethnicity & Malay & 64 & 82 \\
& Chinese & 9 & 12 \\
& Other & 5 & 6 \\
Program & BA Ed & 23 & 30 \\
& BEd & 18 & 23 \\
Age & BSc Ed & 37 & 47 \\
& & Mean & SD \\
& All & 22.243 & 1.059 \\
& Females & 22.266 & 1.132 \\
& Males & 22.166 & 0.785 \\
\hline
\end{tabular}

\section{Instruments}

We used four instruments to collect research data and these were: (1) the researcher-constructed demographical questionnaire; (2) the short 24-item Personal Attributes Questionnaire, PAQ, developed by Spence, Helmreich and Stapp, 1974; (3) the 21-item Attitudes toward Women Scale - British Version, AWS-B, designed by Smith and Walker, 1991; and (4) the Interpersonal Trust Scale, ITS - of Rotter (1971). The PAQ is a 5-point semantic differential scale with two bipolar adjectives (words or sentences) at the two extreme ends of each item. Underlined poles show the direction of the scoring order. This scale consists of three 8-item subscales named Masculinity (M), Femininity (F), and Masculinity-Femininity (M-F). The subscales measure stereotypical roles and behaviors attributed to each gender ( $\mathrm{M}$ and $\mathrm{F}$ ) as well as the androgynous stereotypes that appeal to both genders (M-F). According to factor analysis by Smith and Walker (1991), the AWS-B items comprise three main factors or subscales called Equal Division of Labor (EDL), Moral Equality (ME), and Equal Social Roles (ESR). All the 21 items have 5-point Likert-type scales. In addition, nine of the items require reverse scoring. We used only those items that loaded 0.300 and above on the three clear and interpretable factors generated by Smith and Walker (1991) and these were EDL - 8 items, ME (4), and ESR (5). The ITS (Rotter, 1971) measures one's expectation that the behavior, promises, or statements of other individuals can be relied upon (Robinson, Shaver \& Wrightsman, 1991). All the instruments' 21 items have 5-point Likert scales. This scale can be divided into two main subscales by factor analysis but we used only 12 items that usually load high and positively on the first factor named "Trust of Peers and other Familiar Social Agents" by Robinson, Shaver, \& Wrightsman (1991). The descriptive statistics and reliability coefficients for the subscales are presented in Table 2. 
Table 2. Reliability of the data collection instruments $(\mathrm{N}=78)$

\begin{tabular}{|c|c|c|c|c|c|c|}
\hline \multirow[t]{2}{*}{ Scale } & \multirow[t]{2}{*}{ Subscale(s) } & \multirow[t]{2}{*}{ Items } & \multirow[t]{2}{*}{ Mean } & SE & SD & Alpha \\
\hline & & & & \multicolumn{3}{|l|}{ Mean } \\
\hline \multirow{3}{*}{$\begin{array}{l}\text { Personal Attributes Questionnaire } \\
\text { (PAQ) }\end{array}$} & Masculinity Scale (M) & 8 & 45.923 & 0.475 & 3.548 & 0.824 \\
\hline & Feminity Scale (F) & 8 & 29.833 & 0.410 & 3.576 & 0.705 \\
\hline & $\begin{array}{l}\text { Masculinity-Feminity Scale } \\
(\mathrm{M}-\mathrm{F})\end{array}$ & 8 & 22.628 & 0.385 & 3.400 & 0.726 \\
\hline \multirow{4}{*}{$\begin{array}{l}\text { Attitudes towards Women } \\
\text { Scale-British Version (AWS-B) }\end{array}$} & Equal Division of Labour & 8 & 16.165 & 0.455 & 4.020 & 0.794 \\
\hline & $(\mathrm{EDL})$ & & & & & \\
\hline & Moral Equality (ME) & 4 & 12.884 & 0.290 & 2.568 & 0.701 \\
\hline & Equal Social Roles (ESR) & 5 & 12.512 & 0.339 & 2.895 & 0.783 \\
\hline Interpersonal Trust Scale (ITS) & $\begin{array}{l}\text { Trust of Peers (TP) and } \\
\text { Familiar Agents }\end{array}$ & 12 & 39.025 & 0.636 & 5.622 & 0.817 \\
\hline
\end{tabular}

The correlations in Table 3 may be interpreted in many ways. In terms of absolute values, both the low and non-significant correlations and the low but significant correlations suggest that the scales are measures of different constructs and do not replicate each other. These correlations provide good quantitative evidence for the scales' discriminant validity. The low but significant correlations imply that the scales (to a small extent) might be overlapping and measuring the same construct but the amount of duplication or common variance $\left(\mathrm{r}^{2}\right)$ is little and negligible. The paired scales can thus be said to have satisfactory discriminant validity and low convergence validity.

Table 3. Intercorrelations of the subscales $(\mathrm{N}=78)$

\begin{tabular}{lllccccc}
\hline & Subscales $\dagger$ & 1 & 2 & 3 & 4 & 5 & 6 \\
\hline 1. & M - Scale & 1 & & & & & \\
2. & F - Scale & $0.495 * *$ & 1 & & & & \\
3. & M - F Scale & $0.497 * *$ & -0.083 & 1 & & & \\
4. & EDL - Scale & 0.146 & -0.165 & $0.307 * *$ & 1 & & \\
5. & ME - Scale & 0.099 & 0.055 & -0.048 & $0.423 * *$ & 1 & \\
6. & ESR - Scale & 0.053 & -0.128 & $0.245 *$ & $0.584 * *$ & $0.361 * *$ & 1 \\
7. & TP - Scale & $0.252 *$ & 0.065 & 0.248 & -0.065 & $-0.241 *$ & 0.043 \\
\hline
\end{tabular}

$\dagger$ For full names of subscales see Table 2

$* \mathrm{p}<.05$ (2-tailed)

$* * \mathrm{p}<.01$ (2-tailed)

\section{Data Analysis}

The quantitative data were analyzed by both descriptive statistics (frequencies, percentages, mean and standard deviation) and inferential statistics (t-tests for independent samples incorporating ANCOVA F, Pearson's correlation, and One-Way ANOVA). The rationale and justification for using these techniques is two-fold. First, the procedures were deemed to be appropriate for addressing the research objectives. Second, the data were obtained from a random sample and there was no violation of the statistical assumptions.

\section{Procedures}

Prior to collecting the data, the participants were told about the purpose and objectives of the study. No deception was involved in the study. In addition, the participants were told both verbally and in writing about the ethical conditions or requirements for being involved in the study. The discussion on this topic centered on issues 
of voluntary participation, privacy, anonymity, confidentiality, physical and psychological harm, debriefing, and informed consent. Students were given ample time to reflect on and withdraw from the study if they felt uncomfortable with the research's purpose and objectives. The participants voluntarily agreed to participate in the study. With regard to English language problems, the meanings of difficult English words, sentences and phrases on the instruments were verbally explained to the participants. Furthermore, students at the participants' university take most courses in English language and have participated in many research studies that required them to complete self-report scales / questionnaires in English. The researchers therefore deemed it not necessary to translate the instruments into Bahasa Melayu (Brunei's mother tongue and official language). The study met the ethical requirements for using human participants in research stipulated by the participants' university, the Government of Brunei, and the Helsinki Declaration.

\section{Results}

The findings of the study are presented below according to the three main objectives of the investigation.

\subsection{Differences in Personal Attributes, Attitudes to Women and Interpersonal Trust by Gender}

According to Table 4, males have more of the M-F, EDL and ESR attributes than females. No other significant gender differences were obtained on the variables listed in Table 4.

Table 4. Means, standard deviations and T-values by gender $(\mathrm{N}=78)$

\begin{tabular}{llllllll}
\hline Scale $\dagger$ & \multicolumn{2}{l}{ Females $(\mathrm{n}=60)$} & \multicolumn{2}{l}{ Males $(\mathrm{n}=18)$} & ANCOVA & $\mathrm{T}$ & $\mathrm{P}$ \\
\hline & Mean & SD & Mean & SD & F & $(d f=76)$ & $(2$-tailed $)$ \\
$\mathrm{M}$ & 26.916 & 4.279 & 29.000 & 3.581 & 0.273 & -1.875 & 0.065 \\
$\mathrm{~F}$ & 29.850 & 3.526 & 29.611 & 4.031 & 0.030 & 0.244 & 0.808 \\
$\mathrm{M}-\mathrm{F}$ & 22.033 & 3.303 & 24.611 & 3.012 & 0.343 & -2.960 & $0.004 * *$ \\
$\mathrm{EDL}$ & 15.833 & 3.853 & 19.166 & 3.552 & 0.411 & -3.274 & $0.002 * *$ \\
$\mathrm{ME}$ & 12.633 & 2.550 & 13.722 & 2.515 & 0.099 & -1.593 & 0.115 \\
$\mathrm{ESR}$ & 13.316 & 2.902 & 15.388 & 2.831 & 0.080 & -2.671 & $0.009 * *$ \\
$\mathrm{TP}$ & 39.033 & 5.701 & 39.000 & 5.509 & 0.016 & 0.022 & 0.983 \\
\hline
\end{tabular}

$\dagger$ Full subscale names are presented in Table 2

$* * \mathrm{p}<.01$ (2-tailed)

\subsection{Differences in Personal Attributes, Attitudes to Women and Interpersonal Trust by Training Program}

Evidence in Table 5 revealed no significant differences among participants on the listed variables by teacher education program enrolled in.

Table 5. Means, standard deviations and $\mathrm{F}$-values by training program $(\mathrm{N}=78)$

\begin{tabular}{|c|c|c|c|c|c|c|c|c|c|}
\hline & $\begin{array}{l}\text { BA Ed }^{\mathrm{a}} \\
(\mathrm{n}=23)\end{array}$ & & $\begin{array}{l}\mathrm{BEd}^{\mathrm{b}} \\
(\mathrm{n}=18)\end{array}$ & & $\begin{array}{l}\text { BSc Ed } \\
(\mathrm{n}=37)\end{array}$ & & $\mathrm{F}$ & $\mathrm{P}$ & Eta Squared \\
\hline Scale $\dagger$ & Mean & SD & Mean & SD & Mean & SD & $(d f=2,77)$ & (2-tailed) & \\
\hline M & 27.260 & 5.250 & 27.944 & 4.151 & 27.397 & 4.200 & 0.195 & 0.823 & 0.005 \\
\hline $\mathrm{F}$ & 30.782 & 3.988 & 29.388 & 3.927 & 29.378 & 3.191 & 1.219 & 0.301 & 0.031 \\
\hline M-F & 22.956 & 3.444 & 22.777 & 3.263 & 22.351 & 3.505 & 0.242 & 0.785 & 0.006 \\
\hline EDL & 15.565 & 4.377 & 16.555 & 2.894 & 17.270 & 4.214 & 1.287 & 0.282 & 0.033 \\
\hline ME & 12.521 & 2.777 & 12.055 & 2.817 & 13.513 & 2.193 & 2.357 & 0.102 & 0.059 \\
\hline ESR & 12.956 & 2.915 & 13.500 & 3.053 & 14.459 & 2.949 & 1.940 & 0.151 & 0.049 \\
\hline ТP & 38.565 & 5.185 & 40.000 & 7.095 & 38.837 & 5.172 & 0.362 & 0.698 & 0.010 \\
\hline
\end{tabular}

$\dagger$ See Table 2 for subscale names

${ }^{\mathrm{a}} \mathrm{BA}$ Ed $=$ Bachelor of Arts in Education

${ }^{\mathrm{b}} \mathrm{BEd}=$ Bachelor of Education

${ }^{\mathrm{c}} \mathrm{BSc} \mathrm{Ed}=$ Bachelor of Science in Education 


\subsection{Differences in Personal Attributes, Attitudes to Women and Interpersonal Trust by Ethnicity}

The findings in Table 6 show no significant differences on these variables by ethnicity.

Table 6. Means, standard deviations and F-values by ethnicity $(\mathrm{N}=78)$

\begin{tabular}{llllllllll}
\hline Scale $\dagger$ & \multicolumn{3}{l}{ Malay $(\mathrm{n}=64)$} & \multicolumn{2}{l}{ Chinese $(\mathrm{n}=9)$} & \multicolumn{2}{l}{ Others $(\mathrm{n}=5)$} & $\mathrm{F}$ & $\mathrm{P}$ \\
& Mean & $\mathrm{SD}$ & Mean & SD & Mean & SD & $(d f=2,77)$ & (2-tailed) & Eta Squared \\
\hline $\mathrm{M}$ & 27.453 & 4.174 & 27.111 & 3.982 & 27.200 & 5.761 & 0.031 & 0.969 & 0.001 \\
$\mathrm{~F}$ & 30.015 & 3.287 & 28.444 & 5.876 & 29.794 & 3.623 & 0.769 & 0.467 & 0.020 \\
$\mathrm{M}-\mathrm{F}$ & 22.859 & 3.236 & 21.000 & 3.570 & 22.600 & 5.029 & 1.186 & 0.311 & 0.031 \\
$\mathrm{EDL}$ & 16.687 & 4.143 & 17.111 & 3.059 & 14.600 & 4.037 & 0.701 & 0.499 & 0.018 \\
$\mathrm{ME}$ & 12.937 & 2.629 & 12.666 & 2.291 & 12.600 & 2.701 & 0.075 & 0.928 & 0.002 \\
$\mathrm{ESR}$ & 14.062 & 3.100 & 12.333 & 1.581 & 13.000 & 2.162 & 1.519 & 0.226 & 0.039 \\
$\mathrm{TP}$ & 38.734 & 5.875 & 39.444 & 3.395 & 42.000 & 5.385 & 0.806 & 0.450 & 0.021 \\
\hline
\end{tabular}

\section{Discussion}

The sample was made up of current students. No group (by gender, program and ethnicity) of these modern students is heavily influenced by traditional stereotype behaviors except on the M-F scale where males scored significantly higher than females on PAQ androgynous stereotype items that appeal to both genders. The fact that there were no significant differences between males and females on the M and F variables of the PAQ scale suggests that Brunei male student teachers have no superiority complexes over women that normally are associated with gender-based stereotype thoughts and behaviors and are now willing to let female counterparts to perform roles and responsibilities that were reserved for males in a typical male dominated traditional society. Conversely, females have also no inferiority complexes when dealing with male counterparts. Another important finding from the present study is that all categories of trainee teachers examined in the present study subscribed to the notion of equality of genders in terms of distribution of labor, moral values, and social roles. The males' significantly higher mean scores on the EDL and ESR subscales imply that they are not conservative and would be quite willing to accept, respect and work cordially with female counterparts who may be promoted to leadership positions. The participants' high scores on the TP subscale of the ITS inventory are evidence that they have developed trust in each other. It appears that some of the teaching strategies (such as cooperative learning) used widely during the training of teachers are having a positive impact on teachers' social behavior but this speculative claim is not based on direct evidence from the present study.

\section{Conclusion}

Based on the outcomes, the two genders do not differ significantly in personal attributes, attitudes to women, and interpersonal trust variables investigated in the present study. Both genders support notions of equality regarding the distribution of labor, moral values, and social roles. Modern practices seem to be on the increase while stereotype behaviors appear to be declining. These findings point to good positive social development in Brunei in the future. We recommend a replication of the study using a mixed-methods approach to confirm these results and gain further insights into the issues.

\section{Limitations}

The present study was informed by three main limitations. First, as a survey the results cannot establish cause-and-effect relationships in the variables investigated. Second, a qualitative interview component is missing but was necessary to triangulate findings from the quantitative survey. Third, no attempt was made to obtain criterion-related validity of the scales used due to concerns that student teachers were too busy with exam preparations towards the end of the semester and did not have a lot of time to complete many questionnaires at the time of data collection.

\section{References}

Haq, F. S., \& Mundia, L. (2013). The assessment of psychological distress in Brunei female, mature age and part-time student teachers: Counseling implications. European Journal of Educational Studies, 5(1), $87-100$. 
Haq, F. S., \& Mundia, L. (2012). Comparison of Brunei pre-service student teachers' attitudes to inclusive education and specific disabilities: Implications for teacher education. Journal of Educational Research, 105(5), 366-374. http://dx.doi.org/10.1080/00220671.2011.627399

Hamid, M. H. S., Shahrill, M., Matzin, R., Mahalle, S., \& Mundia, L. (2013). Barriers to mathematics achievement in Brunei secondary school students: Insights into the roles of mathematics anxiety, self-esteem, proactive coping, and test stress. International Education Studies, 6(11), 1-14.

Mundia, L. (2012a). The mental health profiles of student teachers: Relevance to teacher education and in identifying potential future teacher problems. The Internet Journal of World Health and Societal Politics, $7(2)$.

Mundia, L. (2012b). Policy changes in Brunei teacher education: Implications for the selection of trainee teachers. The Education Forum, 76(3), 326-342. http://dx.doi.org/10.1080/00131725.2012.682489

Mundia, L. (2012c). Assessment of GenNEXT learning outcomes at the University of Brunei Darussalam: A qualitative review of selected opportunities, benefits and challenges in human resource development. Journal of International Education and Leadership, 2(3).

Mundia, L. (2012d). The Assessment of Mathematics Learning Difficulties in a Primary Grade 4 Child with High Support Needs: Mixed Methods Approach. International Electronic Journal of Elementary Education, $4(2), 347-366$.

Mundia, L. (2011a). Effects of psychological distress on academic achievement in Brunei student teachers: Identification challenges and counseling implications. Higher Education Studies, 1(1), 51-63. http://dx.doi.org/10.5539/hes.v1n1p51

Mundia, L. (2011b). Social desirability, non-response bias and reliability in a long self-report measure: Illustrations from the MMPI-2 administered to Brunei student teachers. Educational Psychology, 31(2), 207-224. http://dx.doi.org/10.1080/01443410.2010.545049

Mundia, L., \& Bakar, H. A. Z. B. A. (2010). The suitability of the EPQ-R short scale for counseling Brunei student teachers when administered in English and Malay languages. Compare, 40(5), 641-658. http://dx.doi.org/10.1080/03057920903478654

Mundia, L. (2010a). The status of a trainee teacher with mental health problems: Dilemmas on inclusion and exclusion in higher education. Global Journal of Health Science, 2(2), 172-183.

Mundia, L. (2010b). Brunei trainee teachers' coping strategies for stressful situations. International Journal of Psychological Studies, 2(1), 79-88.

Mundia, L. (2010c). Prevalence of depression, anxiety and stress in Brunei student teachers. Internet Journal of Mental Health, 6(2). $\quad$ Retrieved from http://www.ispub.com/journal/the_internet_journal_of_mental_health.html

Mundia, L. (2010d). Implementation of SPN21 curriculum in Brunei Darussalam: A review of selected implications on school assessment reforms. International Education Studies, 3(2), 119-129.

Mundia, L. (2010e). Problems in learning mathematics: Comparison of Brunei junior high school students in classes with and without repeaters. Journal of Mathematics Research, 2(3), 150-160.

Mundia, L. (2009). Implementation of inclusive education in Brunei Darussalam: Review of possible implications on school counselors. Electronic Journal for Inclusive Education, 2(4). Retrieved from http://www.cehs.wright.edu/ prenick/Spring_Summer09_Edition/spr_sum09.html

Robinson, J. P., Shaver, P. R., \& Wrightsman, L. S. (1991). Measures of personality and social psychological attitudes. San Diego, CA: Academic Press.

Rotter, J. B. (1971). Generalized expectancies of interpersonal trust. American Psychologist, 26, 443-452. http://dx.doi.org/10.1037/h0031464

Smith, M., \& Walker, I. (1991). Evaluating the British version of the Attitudes toward Women Scale. Australian Journal of Psychology, 43(1), 7-10. http://dx.doi.org/10.1080/00049539108259089

Spence, J. T., Helmreich, R., \& Stapp, J. (1974). The Personal Attributes Questionnaire: A measure of sex role stereotypes and masculinity-femininity. JSAS Catalog of Selected Documents in Psychology, 4, 43-44.

Tait, K., \& Mundia, L. (2012). Preparing teachers to meet the challenges of inclusive education in Negara Brunei Darussalam. In C. I. Forlin (Ed.), Future directions for inclusive teacher education: An international 
perspective (pp. 60-69). Hong Kong: Routledge/Francis \& Taylor.

\section{Copyrights}

Copyright for this article is retained by the author(s), with first publication rights granted to the journal.

This is an open-access article distributed under the terms and conditions of the Creative Commons Attribution license (http://creativecommons.org/licenses/by/3.0/). 